\title{
A CONTEMPORARY REVIEW OF ENGLISH LANGUAGE LITERATURE ON INCLUSION OF STUDENTS WITH DISABILITIES IN PHYSICAL EDUCATION: A EUROPEAN PERSPECTIVE
}

\author{
Deirdre O’Brien \\ EMMAPA Student; Faculty of Physical Culture at Palacky University, Olomouc, Czech Republic \\ Martin Kudláček \\ Faculty of Physical Culture at Palacky University, Olomouc, Czech Republic
}

Peter David Howe

Loughborough University, Peter Harrison Centre for Disability Sport, UK

\begin{abstract}
The state of inclusion for students with disabilities in general physical education (GPE) varies across European countries. In many countries inclusive physical education is still a developing practice. The purpose of this review of literature published in English is to highlight current debates surrounding the inclusion of students with disabilities in physical education, in hope that there might be a degree of consensus of opinion surrounding the facilitation of inclusive practices within Europe. This review covers an eight year period commencing in early 2000. A total of twenty seven articles are highlighted in this review using the Theoretical Model for the Study of Classroom Teaching (Dunkin \& Biddle, 1974) which suggests that study of teaching and learning involve four variables: presage (teacher), context (students), process (interaction) and product. The ultimate aim of this review is to use recent publications in the field of APA to highlight a need for the establishment of professional guidelines for successful implementation of good practice within GPE throughout Europe.
\end{abstract}

KEYWORDS: physical education, integration, inclusion, mainstreaming, and disabilities.

\section{INTRODUCTION}

Authors in the field of adapted physical education articulate different definitions of inclusion. Lieberman and Houston-Wilson (2002) described inclusion as providing services to students with disabilities in the typical classroom environment rather than removing them from it in order to receive 'special' services. To others inclusion is viewed as a cohesive sense of community, acceptance of differences and responsiveness in individual needs (Stainback \& Stainback, 1996). Miller (1994) viewed inclusion as the point in the continuum of services which places the student with a disability in regular education classrooms, with appropriate support personnel, to receive an education and related services alongside peers. Overall the term inclusion is associated with providing services to ensure that all students regardless of their ability can achieve their full potential in an appropriate educational setting.

It is generally believed that all students with disabilities should experience participating in regular physical education lessons with their friends as part of their growth and development (BAALPE, 1996). Research has been conducted in the area of including students with disabilities in mainstream schools, but research directly associated with physical education is still in short supply. Research conducted recently however suggests that inclusion in physical education can effectively work for the child with a disability (Goodwin \& Watkinson, 2000) and this can be achieved without negatively affecting peers without disabilities (Faison-Hodge \& Porretta, 2004; Obrusníková, et al., 2003). It is essential for educators to determine how much support a child needs to receive appropriate physical education within 
the general physical education (GPE) setting (Block \& Krebs, 1992) since within physical education there is believed to be a continuum of placement options with different levels of inclusion (Block, 2007). Inclusion of students with disabilities in GPE has been the focus of growing number of studies in the last 20 years. Block and Vogler (1994) reviewed literature with regard to inclusive school settings. Their initial findings were favourable towards inclusion. More recently Block and Obrusníková (2007) reviewed a ten year period from 1995 to 2005 and they concurred with the earlier findings of Block and Vogler (1994) also found numerous positive outcomes of inclusion in GPE.

\section{METHOD}

This review examines the literature regarding inclusion of students with disabilities in physical education from the year 2000 to 2008. Various databases were accessed, these including SPORTDiscus, Health Medline, ProQuest and PsycINFO. A grand total of 114 articles were sourced from a broad selection of journals. Conscious of the inadequacy of many of the articles' relevance to the literature review, the researcher re-examined the articles and applied a specifically designed five criteria to increase the focus of the study: (a) must be published in English, as this is the first language of two of the three authors, (b) must be directly related to physical education or physical activity with a focus on inclusion, (c) must be an original study; (d) must be published between 2000 to 2008, and (e) must be published in journals, thus excluding books, unpublished papers, doctoral dissertations and master theses. Having sourced 114 articles originally, 27 proved suitable after implementing the selection criteria. The review that follows is based upon the Theoretical Model for the Study of Classroom Teaching (Dunkin \& Biddle, 1974) adopted within inclusive PE by Kudláček (2006b). In the 1974 Dunkin \& Biddle suggested that study of teaching and learning involve four key variables: presage (teacher), context (students), process (interaction) and product. Presage variables include those influencing teaching behaviour of $\mathrm{PE}$ teachers. Context variables include background of students, their skills, and attitudes toward physical activities or previous experiences. Process variables include student-student interaction, teacher-student interaction, teacher behaviours and student behaviours. Within the sample of articles the prevalence of focus upon the variables articulated by Dunkin and Biddle (1974) was a follows (a) Presage variables - teachers (13 articles), (b) Context variables - students (2 articles), (c) Process variables - interaction in inclusive PE (9 articles), and (d) Product variables - effectiveness of inclusive PE (3). Some of the articles related to more than one key area as various authors investigated more than one variable within a study with particular overlap of issues related to process and product variables.

\section{RESULTS}

\section{Presage variables - Teachers in Inclusive Physical Education}

In accordance with Theoretical Model for the Study of Classroom Teaching (Dunkin \& Biddle, 1974) articles focusing on teacher formative experiences, teacher training experiences, and teacher properties were included in the presage variables results.

\section{Preservice Training of Teachers}

In accordance with Sherrill (2004) it is important to prepare future physical education teachers engage with inclusive practices for students with disabilities in GPE settings. In order to prepare these teachers-in-training we must be able to measure and to understand their attitudes towards inclusion. Hodge et al. (2003) selected a purposeful sample of ten teachers-intraining all majoring in physical education and enrolled in an adapted physical education (APE) course to explore the meaning of practicum experiences. Over an eight week period as part of the APE course students participated in a Unified Physical Activity Program (UPAP). Data were collected via selfreflective journals. Results from the study revealed that the experience of planning and incorporating inclusive practices impacted favourably on the teachers-in-training overall 
confidence and attitudes towards teaching children with disabilities. At the end of the study teachers-in-training showed a positive attitude to an integrated physical activity environment. Establishing a routine with the children, having a variety of activities and carefully planning each lesson with a readiness for flexibility were aspects evident of the students' teaching that worked well. This allowed for meaningful interactions and experiences. The UPAP program was a great initial starting point for these students to gain a hands-on experience. Hodge et al. (2003) further highlighted that many of the experiences and skills gained through this practicum can be easily transferred into a physical education class environment.

In another study Hardin and Brent (2005) explored how the Physical Education Teacher Education training curriculum has affected the competence and confidence of practising physical education teachers. Five newly qualified teachers who taught students with disabilities were selected to be interviewed enquiring about their education, training and inclusion in physical education. The assortment of Q-sort cards (file cards that contain personality statements) that teachers had to organise and rank in accordance with their self-understanding Results from the Qsort cards revealed that teachers felt that the experience of teaching was the best resource for learning how to teach students with disabilities. Other teachers and course work were also seen as vital tools. The majority of the teachers' experience of course work was only based upon one class taken on adapted physical activity with three of the five teachers not experiencing teaching students with disabilities during this time. Hardin and Brent (2005) commented that one class of training for teachers in adapted physical education is not sufficient. This assertion is in line with the thoughts of Kozub et al. (1999) who have suggested that teacher training has a large impact on how future physical education teachers develop their knowledge of disabilities and their understanding of differences in students. The understanding of students with disabilities and their associated differences is a stepping stone to overall acceptance and inclusion within physical education settings.

Attitudes of PE teachers towards inclusion

A vital part of inclusion is the teachers' attitudes. Attitudinal instruments are vital tools for researchers, as they provide them with a means of collecting their data and analyzing it. Various instruments have been used throughout the studies in this review. The Physical Educators' Judgements about Inclusion (PEJI) instrument was developed by Hodge et al. (2002). This instrument is designed to establish the attitudes of physical education teacher education (PETE) pre-service teachers towards inclusion of students with disabilities in GPE. The instrument constitutes three areas of exploration (a) Social Judgement, (b) Contact, and (c) Planned Behaviour, which together can be analysed to establish teaching competence as it relates to inclusive aims. Eighteen PETE pre-service and experienced teachers were selected for the focus group, which comprised ten females and eight males. All participants had taken at least one course on teaching students with disabilities in PE. To generate validity of the new instrument, it was distributed to two hundred and seventy two PETE pre-service teachers. Three main subscales were revealed from the study, these being: (a) judgements about inclusion versus exclusion, (b) judgements about acceptance of students with disabilities, and (c) judgements about perceived training needs.

Kudláček et al. (2002) developed instrument based on the Theory of Planned Behaviour developed by Ajzen (1991). The Attitude Towards Inclusion of Students with Physical Disabilities in Physical Education (ATIPDPE), which was later revised by Kudláček (2006a) to ATIPDPE-R having greater number of items in attitudinal subscale following suggestions from previous studies using ATIPDPE. This instrument measures three psychological components of Inclusive Physical Education (IPE): (a) attitudes toward IPE, (b) subjective norm toward IPE, and (c) perceived behavioural control in relation to IPE.

Teachers' perceptions of students' abilities (Karper \& Martinek, 1985) have an impact on 
both student learning opportunities and participation. Smith (2004) purposively selected seven experienced teachers to interview. He examined the inclusion of students with Special Educational Needs (SEN) in secondary school physical education. The use of open questions provided a greater range of questions and the opportunity to probe certain topics which arose in the interviews. Results illustrated the demands teachers face with inclusion. Teachers believed it was unsuitable to teach a full class of twenty eight students and also include SEN students within this context. 'Equal opportunities for all' was the general philosophy of all teachers, yet many students with SEN were not given the same opportunities as their peers. While team games were a strong and traditional part of the curriculum, all teachers collectively stated this area as the most difficult within which to actively engage in inclusive practices. Teachers highlighted individual activities as much more appropriate for instigation inclusive practices but this by there very nature make it difficult to institute a philosophy of inclusion. Smith (2004) outlined that often students with SEN are expected to 'fit' into the curriculum, rather than adaptations made to ensure the inclusion of these students. He further suggests that for inclusion to take place, the curriculum needs to be more flexible and to move away from the strong focus on team sports. This study was one of the few to be based solely upon qualitative data and as such interpretation of result maybe opens to continued reinterpretation. In another study Morley et al. (2005) explored the perceptions of forty three secondary school teachers' views towards inclusion in mainstream physical education. Understanding, awareness, extra planning and organisation were highlighted as variables the teachers were aware that needed to be adapted. Teachers' perceptions of their own inadequacy and lack of confidence were mentioned, 'you want to help them; you want them to do their best, you want to include them but it's knowing how to adapt it (teaching and instructions) to suit them' (Morley et al., 2005). This suggests that Indoor and individual activities were seen as easier to include students in, while outdoor and team activities were viewed as more problematic. The severity and type of disability was cause for concern as behavioural and emotional impairments were deemed the most challenging for successful inclusion. Teachers also remarked on the effect on the students without disabilities, 'I do think about other members of the group wondering if that person is holding them back' (Morley et al., 2005). Morley et. al. also highlight that the majority of teachers commented on the inadequate and lack of resources and support, and teacher training. Regarding training they commented, 'None at all, we are not trained' or 'It wasn't catered for in my teacher training' (Morley et al., 2005).

Teachers' Concerns and Perception about Barriers in Inclusive PE

For teachers to feel somewhat apprehensive about taking students with disabilities into their physical education is understandable. They would naturally wonder as to how they are going to include and motivate all students with and without disabilities. Lienert et al. (2001) interviewed thirty physical educators from Germany and United States to discover the concerns teachers have in regard to inclusion of students with and without disabilities in physical education. Purposeful sampling was used to select sixteen teachers from Berlin and fourteen from Texas. This study was directed by the Concerns-Based Adoption Model (CBAM). An interview guide comprised semi-structured questions and a demographic questionnaire was used. Concerns were reported for four of the seven stages of the CBAM, which were: (a) personal, (b) management, (c) consequence, and (d) collaboration, with management being of paramount importance. Culturally the teacher in the United States had more personal concerns and worries about everyday demands and competency to meet those demands the needs of pupils with disabilities. Some teachers in the United States did not try to teach the students with disabilities, instead they handed over responsibility to the paraprofessionals. The German teachers felt it was very important to have the choice whether to teach integrated classes or not. This research 
suggests that all teachers were unsatisfied with facilities, equipment and the high ratio of students with disabilities in their classes. Collaboration in a supportive environment was collectively viewed as highly important by teachers in both countries. Encouragingly overall in both countries the teachers stated that the positive effects of inclusion were far greater than the negative effects.

Similarly Hodge et al. (2004) examined the beliefs and behaviours of nine secondary school physical education teachers in relation to including students with disabilities. This study again uses purposeful sampling to select the seven male and two female experienced teachers. Results from the interviews and questionnaires outlined that teachers expressed both positive and negative beliefs about inclusion. On the positive side the teachers who contributed to the study felt that inclusion was 'good' conceptually but often there were many barriers to overcome to achieve successful inclusion. The inability to give the time and individual attention to the students especially those with severe disabilities due to lack of support was a recurring theme. The majority of teachers commented that the availability of support impacted upon the efficacy of their teaching. Many teachers did not know how to adequately adapt their teaching environments to be safe and inclusive. The pre-service training of these teachers indicated that only five out of the nine had an adapted physical education module included in their undergraduate studies. However nine participants in a study is a relatively small number to ensure that a genuine and varied perspective of PE teachers was obtained.

Meegan and MacPhail (2006) questioned general expectations of physical education teachers to be fully committed to teaching students with disabilities, suggesting thatinstitutions of higher education are failing to prepare teachers-in-training with the skills required for the inclusion of all students. In another study that examined the barriers of GPE teachers when including students with visual impairments, Lieberman et al. (2002) found that the most common barrier identified was a deficit in professional preparation. An in-service workshop on physical education for students with visual impairments was attended by one hundred and forty eight teachers, who had visually impaired students in their physical education classes. A questionnaire distributed prior to the workshop was used to determine the perceived barriers facing teachers. Results disclosed that $66 \%$ of teachers found lack of professional preparation as the main barrier. Other barriers identified were lack of equipment (63\%) and programming or curriculum (57\%). Many teachers felt unprepared to incorporate students with visual disabilities into the class. Lieberman and colleagues suggested that the curriculum of the teacher training programmes needs to be altered to meet the needs of physical education teachers. Teacher training is a clear problematic area with regard to inclusion, but it is a problem that can be rectified.

Fejgin et al. (2005) used a questionnaire to examine the relationship between inclusion and burnout in physical education. The data were collected from three hundred and sixty three elementary school physical education teachers across six districts in Israel. Burnout was found to be related to the number of students with SEN in a class, the support available, and work place conditions. A strong correlation was discovered between the structural and social dimensions of a school in relation to causing burnout. These teachers also viewed inclusion as problematic because of the additional time requirements, the discipline of students, evaluation and classroom management depending on the severity of the students' impairments. Behaviour, learning problems and lack of support was another area linked to burnout. Similarly to other studies Fejgin et al. (2005) highlighted that teachers do not have any pre-service training on how to include students with SEN in physical education. This is a recurring trend seen throughout many countries.

The studies in this section used a combination of interviews and questionnaires to retrieve their data. One study used an interview, two studies used questionnaires and one study used a combination of both. The outcomes varied throughout these studies. 
Overall, the main concerns and barriers identified were professional preparation, management and support.

Support Personnel in Inclusive Physical Education

Equal participation between all students in $\mathrm{PE}$ is strengthened by a combination of teacher and APE consultant, teacher and teacher assistant or teacher and peer tutor support systems (Murata \& Jansma, 1997). Two main sources of support personnel, paraeducators and APE teachers were identified in the articles consulted for this review, were considered vital to inclusive practices. Davis et al. (2007) distributed questionnaires to determine what actual were the responsibilities and training needs of paraeducators within physical education. Seventy six paraeducators responded to the questionnaire (99\% female). Responses in this study revealed $61 \%$ believed that they were adequately trained for physical education, but surprisingly only $16 \%$ had received training in adapted physical education. The majority of the paraeducators interviewed had simply completed one-day training course. $38 \%$ participated in physical education with a student. The level of participation varied greatly from the majority escorting the students and giving prompt cues to directly working with the students during PE. Assisting in assessment and sharing individual educational plan (IEP) suggestions was carried out by $28 \%$. Paraeducators felt they needed to know the IEP goals of each child to help develop and reinforce those goals. Encouragingly 90\% were willing to be trained in physical education, but requesting incentives to do so. Authors highlighted five responsibilities that paraeducators can improve in physical education with students. These responsibilities were: (a) assistance with social interaction, (b) transfer from one activity to the next, (c) safety, (d) interaction with students, and (e) cooperative learning among students and reinforcing instructions for the teacher.

Probably the best and most effective form of support to a physical education teacher is that of the adapted physical education teacher. They have undergone specialised training and have a true understanding of the inclusion process. A study by Lytle and Collier (2002) investigated APE specialists' perceptions of consultation. Six participants were involved in the study, four female and two male, with age ranging from thirty five to forty six years and case loads of students ranging from twenty four to one hundred and ten. Data was collected through interview, field observations, researcher notes and focus group interactions. Results indicated that the skills, attitudes and knowledge of the APE specialist combined with the educational environment were influential factors in the types of services provided. The use of consultations and their implementation were often influenced by the social, intellectual and physical environment. All participants commented that no formal training in consultation was provided as part of their training. In another study Lytle and Hutchinson (2004) explored the experiences and roles of APE teachers primarily through the use of observations and interviews. Experienced teachers in APE were used in the study, four being female and two male. When the data were analysed various roles of the APE teacher were presented: (a) advocator, (b) educator, (c) courier, (d) resource coordinator, and (e) supporter/helper. There were some negative reactions to the supporter/helper role, as the situation of territorial issues with the GPE teacher often arose. Overall it was highlighted that the various roles in the consultation process is a huge part of the APE teacher's daily life. Specific training in consultation was not part of the participants' APE training. Lytle and Hutchinson suggested that more training in areas such as adult interactions and effective communication in the consultation process is required.

Kudláček et al. (2008) studied the nature of work and roles of public school adapted physical educators in selected school districts in the United States with the aim of adding to the information base to enable the improvement of service delivery and professional preparation. Participants of the study were 6 females and 2 males with experience teaching (range of 2-23 years) in the field of APE. Data collection included individual in depths interviews, demographic 
data sheets and interview notes. Results showed the differences in the nature of work among APE specialists. Participants had high teaching loads (44-90 students) and served wide range of schools (1-20), which created quite different teaching profiles. Most teachers were involved in APE consulting. Results also indicated the needs to incorporate issues of consulting into teacher preparation and change the university studies more relevant to "real life teaching”.

\section{Context Variables - Students in Inclusive Physical Education}

Dunkin and Biddle (1974) highlighted in their Theoretical Model for the Study of Classroom Teaching the importance of studying students in learning process. Under context variables they focused on learner properties (students with and without disabilities), and school, community and classroom contexts.

\section{Students without disabilities}

The perception and attitudes of students without disabilities can have a substantial impact on the success of inclusion in a GPE class. From the previous studies inclusion of students with and without disabilities can be successfully implemented. In relation to this Verderber et al. (2003) used the theory of planned behaviour to investigate the intentions of middle school students to engage with students with severe disabilities in GPE. 350 grade sixth to eight students completed the Verderber Inventory of Students' Intention to Participate in Inclusive Physical Education (VISIPIPE), with its validity proved at the commencement of the study. Results indicated that students believed they should work and play with students with severe disabilities, but these beliefs were primarily motivated by abiding with the beliefs of parents and teachers. In comparison students did not believe that friends had the same beliefs. Overall the study showed that teachers and parents can have an influence on middle grade student's beliefs and attitudes towards others.

Other study, using the theory of planned behavior Kodish et al. (2006) examined the determinants of physical activity in an inclusive setting. Kodish and colleagues used four classes containing one hundred and fourteen students aged ten to thirteen. Class one (C1) and class three (C3) were physical education classes that each had four students with autism included in them $(n=63)$, while class two (C2) and class four (C4) were GPE classes without students with identified disabilities included $(n=51)$. None of the students with autism has received any direct support within physical education. The physical education teacher used the Dynamic Physical Education Curriculum (DPE) which is positive towards inclusion. Questionnaires and electronic pedometers were used for assessment. The pedometer measured the steps taken and activity time over a two week period. Results showed that student' intentions to be physically active lead in actual behaviour. Results also indicated that the subjective norm and perceived behavioural control were critical predictors of students' intentions to be physically active.

The main message that is outlined in the studies above is that successful inclusion in physical education can take place effectively. The two studies including students with severe disabilities and autism, used questionnaires to establish their results. The third study used a pre and post-test design to establish their results on the inclusion of a student with muscle dystrophy. All the studies revealed that inclusion can be implemented without any negative impact on any of the students.

\section{Process Variables - Interaction in Inclusive Physical Education}

In accordance with Theoretical Model for the Study of Classroom Teaching (Dunkin \& Biddle, 1974) articles focusing on teacher classroom behavior and student classroom behavior were included in the process variables results. Studies describing the nature of interactions in inclusive physical education were selected for this section.

Experiences of Students with Disabilities with Inclusion

The purpose of a quality physical education programme is to direct and provide students with the knowledge and skills to be 
physically active throughout their life (Block, 2007). Due to greater inclusion in schools physical education, teachers will engage students with and without disabilities in the same class (Verderber et al., 2003). It is important to question, however, whether these students want to be included in physical education and whether they experience the same level of physical education as their peers.

Goodwin and Watkinson (2000) used a maximum variation purposeful sampling design when they looked at the experiences of nine elementary students with disabilities in inclusive physical education. These students were wheelchair users in physical education (10-12 years old), data was collected through interviews, field notes and drawings. Goodwin and Watkinson (2000) discussed the students' experiences within the conceptual framework of ecological perception and affordance theory. Themes of sense of belonging, skilful participation and sharing in the benefits were associated with 'good days'. In contrast, themes of social isolation, questioned competence and restricted participation were associated with 'bad days'. Results showed that students with disabilities preferred participation in inclusive $\mathrm{PE}$ rather in segregated setting, or in special program. This study gave insight into the contributing factors of positive and negative experiences of students with disabilities.

Another study by Hutzler et al. (2002) explored the personal experiences of children aged nine to fifteen with physical disabilities in physical education in Israel. The purpose of the research was to identify supporting and limiting mechanisms with regard to the students' inclusion and empowerment. Purposeful sampling was implemented with ten students (8 boys, 2 girls) most of whom were impaired by cerebral palsy. Interviews were conducted in a semi-structured manner with an eleven point rating scale. Results illustrated that $60 \%$ of the students had been teased and ridiculed by other children, through imitating their walk, expressing pity or opening their brace. Forty percents expressed that their peers had been supportive in physical education and twenty percents of students referred to having extracurricular interactions with other children with a disability, but they 'wouldn't like to be seen with them'(page number?). In regard to failures, over half of the comments from the students related to experiencing failure in physical activity.

But what about the other side of the coin? It is vital to explore the affect of inclusion on both students with and without disabilities. Faison-Hodge and Porretta (2004) compared the physical activity levels of students with and without disabilities during physical education and recess. The school was purposively selected as it included students with mental retardation (MR) within a GPE class. Participants in this study were 46 fourth and fifth grade students ( $8-11$ years) with eight students with mild intellectual disabilities. The students' fitness levels were tested by-the Fitnessgram Progressive Aerobic Cardiovascular Endurance Run (PACER). Students wore a heart-rate monitor and were videotaped during physical education and recess. Results indicated that students had higher levels of moderate to vigorous physical activity (MVPA) during recess than physical education. Students with low cardiorespiratory fitness and students with MR had similar levels in both physical education and recess. Faison-Hodge and Porretta (2004) suggest that these results may be due to students undergoing a fitness testing module in physical education. A lot of the time would have been spent on testing, writing results and assisting other students, while recess is free time and open choice of activities for the students with no instruction time. Overall, the study highlights that students with MR can be included in physical education. Due to the school previously including students with MR in their PE classes, these classes would not typically represent the GPE. The findings may not be transferable to all other schools for this reason and results are dependent in part on the severity of MR which can impact on the form of inclusion.

Another study with positive corresponding results towards inclusion emerged from utilizing the Newcomb volleyball lead up game and an adapted version using a balloon. 
Kalyvas and Reid (2003) investigated the effect of sport adaptations on students with and without disabilities using a quasi-experimental factorial design. The factors being studied were participation and enjoyment of thirty five students aged seven to twelve, fifteen of which had a physical disability. These students were split into three different classes for the purposes of the study. Both the adapted and non-adapted games were played for fifteen minutes each for three classes. A combination of systematic observations, individual interviews and questionnaires were used to collect the data. Throughout the three classes students with disabilities preferred the adapted game, discovering it to be more enjoyable and they felt that their peers were more cooperative and helpful during the game. Statements of students without disabilities varied with age, the two younger classes enjoyed both games, finding the adapted game easier to play but still fun. The older students without disabilities considered the use of a balloon frustrating as it was harder to win points and the pace of the game was slower. All students did realise that the adapted game helped their peers with disabilities and did not have any objections to playing the adapted version. Overall during the adapted game all students were skilfully successful and had greater activity levels, indicating that the adapted game did not hinder their performance. Kalyvas and Reid (2003) believe that students with disabilities can be included in GPE programs once appropriate adaptations are made which do not compromise the experience for students without disabilities. If over a longer period of time whilst using adapted games, this approach could have an effect on the attitudes, interest and participation of students with and without disabilities.

The studies showed that experiences of students with disabilities greatly differ, some having good experiences and others having bad ones. Three of the studies focused on inclusion of students with physical disabilities while the fourth studied inclusion of students with intellectual disabilities.

\section{Peer tutoring in Inclusive Physical Education}

Peer tutor has been highlighted as an effective support tool that can be used to assist both the teacher and the student with disabilities. Fenrick and Peterson (1984) found that peer tutoring increased instructional time and helped to develop positive attitudes. The successful training and implementation of peer tutors has provided encouraging results to-date.

Lieberman et al. (2000) explored the effect of peer tutors on the activity levels of deaf students in GPE. Through the use of a purposeful sampling design, eight deaf students were gender matched with eight typically developing peer students. Peer tutors were trained for four to five thirty minute sessions in sign language and basic teaching strategies. An assessment of the tutors' competency was implemented through a theory and practical test. In total of thirty two classes were observed over a five month period. The System for Observing Fitness Instruction Time (SOFIT) was used to collect data. A single subject delayed multiple baseline design across participants was employed. Results showed that there was an increase in moderate to vigorous activity levels (MVPA) for deaf students. Interestingly there was also an increase in the peer tutors' MVPA. All students increased their levels of MVPA by at least 19\%. Lieberman and colleagues (2000) indicated their was a great deal of value added to the peer tutors from studying teaching strategies and engaging in the process of feedback that ultimately helped them and motivate their disabled peers.

Klavina and Block (2008) studied the effect of nine trained peer tutors on the physical, instructional and social interaction behaviours of three students with severe and multiple disabilities (SMD) and peers without disabilities. The study observed forty six GPE classes. Each class was forty five minutes in duration, two to three times a week and containing twenty five to thirty students. Each class was videotaped with each SMD students wearing a microphone. Three instructional support conditions for SMD were used throughout the study: teacher-directed, peerdirected and voluntary peer support. The peer tutors underwent training, they used the Tip to Teach, Assist and Practice manual (TIP-TAP steps). After training, each peer tutor was 
assessed through three trials; a score of 90\% had to be attained. The results showed that during the teacher-directed instructional condition, interaction behaviour between SMD students and other peers was low across all participants. In contrast, the interaction between adult support personnel and SMD students was high. During the peer-mediated instructional condition, interaction behaviours with peer tutors had an immediate increase. Differing from the previous result, interaction behaviours with adult support personnel decreased for all students during the peermediated instructional condition. It was observed by teachers that students with SMD enjoyed being assisted by their classmates. Klavina and Block (2008) have outlined that social interaction behaviours showed low results throughout the study, which could indicate students did not engage in conversations or in nonverbal interactions not related to GPE class. During the voluntary peer support segment, the mean scores of interaction behaviours with other peers, not designated as peer tutors increased for all students with SMD. Inadvertently the teachers' interaction behaviour decreased during voluntary peer support. Overall positive results were denoted from this peer tutoring study from teachers, peer tutors and students with SMD.

Most recently Klavina (2008) studied the effect of peer-mediated and teacher-directed instructions on the activity engagement time of students with severe and multiple disabilities (SMD). She studied inclusive GPE sessions under two kinds of instructional support conditions for three students with SMD: (a) teacher-directed, and (b) peer-mediated. Instructional behaviour data showed that during peer-mediated support conditions the instructions provided by tutors were more frequent than instructions provided by teachers during teacher-directed conditions. Physical behaviour data indicated that peer-mediated conditions resulted in similar levels of physical behaviour for all students with SMD when compared to teachers directed conditions. Also, for all students with SMD the activity engagement time data was higher in conditions where peer tutors were involved.

Peer tutoring is an increasingly popular and highly successful strategy of support within physical education. With appropriate training this resource could be developed to its maximum potential with all students benefiting.

Social Interaction and Active Learning Time in Physical Education (ALT-PE)

Initially the topics of social interaction and ALT-PE were highlighted as two separate areas, but due to a lack of articles corresponding to the research criteria, these have been combined. The social interaction of students is a vital part of physical education. The sense of belonging within a group and creating friendships are valuable skills gained and developed through social interaction (Moffett et al., 2006). Therefore it is important to know whether students with and without disabilities, socially interact in physical education.

To establish this Grenier (2006) investigated an inclusive physical education class with sixteen students over a period of six months. One of the students had severe cerebral palsy and a visual impairment and the study used a social constructionist perspective. The data was sourced from interviews, observations, document review and journals. For the majority of the time, adaptations were made to include all students in the class. When adaptations could not be created, the student with a disability did different activities but with similar goal outcomes to the rest of the class. Students were often paired for activities and a focus on both skill development and social interaction was promoted in the class. Overall, the teaching was focused on the social interactions of students while learning and developing their skills. This led to greater acceptance and understanding of each other in the class. The results from this study were highly positive but could this have primarily been due to the small class size.

Place and Hodge (2001) studied the social inclusion of three girls with physical disabilities and nineteen students without disabilities in GPE during a six week softball 
unit. Data was collected through observations, videotaping of classes and interviews. Analysis of data was conducted through the use of Academic Learning Time for Physical Education (ALT-PE) and the Analysis of Inclusion Practices in Physical Education Form S (AIPE-S). The students with disabilities did not receive any assistance in physical education but did in other subjects. Results indicated that students with and without disabilities rarely engaged in social interaction. The students with physical disabilities tended to stay and work together in class, often at a distance from the other students. Results also suggest the teacher did not emphasise any social interaction during the classes. Students with disabilities often felt neglected and awkwardness was observed between students though there was communication observed between the two groups of student did talk. There was no demonstration, praise or feedback provided by students with and without disabilities, but these interactions did take place between the students with disabilities themselves. Overall during class time, the students with disabilities spent more time on-task compared to their peers. It is evident from this study that social interaction needs to be encouraged and emphasised by GPE teachers.

Within the two contrasting studies, the teachers' focus and goals played a pivotal role in the students' opportunities for social interactions. One of the studies explored the inclusion of a student with cerebral palsy and a visual impairment. The second study looked at the inclusion of three students with physical disabilities. With only two studies in this section it highlights the need for more research in this area.

\section{Product Variables - Effectiveness of Inclusive Physical Education}

Various studies have outlined that students with disabilities can be included in GPE without any negative effects on the other students' learning experience. In accordance with Dunkin and Biddle (1974) model that suggests studying immediate students' growth and long-term effects on learning in inclusive physical education, we have selected articles studying the effect of IPE on learning of students with and without disabilities.

Obrusníková et al. (2003) investigated the effect of inclusion. They used a pre and post test evaluative case study design with a purposively selected sample. The aim was to evaluate the effect of including a student with muscular dystrophy who used a wheelchair into a GPE class of twenty one fourth grade students without disabilities where the student with a disability did not receive any direct support throughout the two weeks volleyball unit. The non-inclusive class comprised of eighteen fifth grade students. Results from the skill and knowledge tests showed that both classes improved on all measures of skills, and there was no significant difference between the gains of the two classes. The results of attitudinal questionnaire CAIPE-R (Block, 1995) results revealed that both groups had positive attitudes, but students in the inclusive class had slightly more accepting attitudes towards students with disabilities. Overall there was no significant difference found between the inclusive and the non-inclusive volleyball class. The results of the study are however based upon a very short time frame for true attitude changes to take place. A follow-up study to see if the attitudes had been maintained or changed would provide more depth to the study.

In another study, Block et al. (2001) conducted a twelve week study to determine the effects of partner training by students without disabilities to students with severe multiple disabilities. Twenty six students with severe multiple disabilities aged five to twenty one attending a Special Education school were partnered with twenty five partners from fifth and sixth grade students from a local school as part of the Special Olympics Motor Activities Training Program (MATP). Pre-testing of motor skills and interviews with parents was taken before the study began. Partners having undertaken four hours of training were assigned to a particular student. During the twelve weeks the teaching of the motor skills was solely the responsibility of the partner. Results showed significant improvement in motor skills and adaptive behaviours in 
students after working with their partners. Observations were conducted by staff members and indicated that while partners and students were working together, partners were quite talkative and students made more effort than usual. Overall the study outlined that the training of students with severe multiple disabilities can be successfully carried out by fifth and sixth grade students once these students are adequately trained.

Similarly Ward and Ayvazo (2006) assessed the effects of class wide peer tutoring (CWPT) in teaching catching skills. The school selected in this study specialized in the inclusion of students with autism. Two students without disabilities and two students with autism in a kindergarten class of sixteen students were selected. Authors focused at the number of catches participants made during each session. These results were used to identify the level of engagement and the work completed by the students. The second measure focused on the number of correct catching skills highlighting which students with disabilities were able to perform skills that their peers were performing. Training of peer tutors was implemented in a single thirty minute session prior to the first intervention. The results indicated that the scores of performance and correct performance of the autistic students increased during peer tutoring session in comparison to their results during whole class instruction. Overall the results were positive, but one might question whether it was primarily due to the individual assistance the students with autism received rather than successful inclusion process of these students.

\section{DISCUSSION}

Currently at undergraduate level of Primary and PE teacher training, there is minimum specific training for APE (Morley et al., 2005). Hands-on practicum experiences in schools, knowledge of the various disabilities, instructional and curricular modifications are examples of key material that needs to be incorporated into teacher training. Greater flexibility is needed in the curriculum of the higher education institutions (Lieberman et al., 2002, Smith, 2004). Immediate intervention and re-structuring of training in these institutions needs to be introduced (Douthwaite, 1990). An example of one such program is the project "European Inclusive Physical Education Training" (www.eipet.eu). This focused on competencies of GPE teachers in relation to IPE and provides guidelines for higher education programme (curriculum) development.

Peer tutoring seems to be well developed and highly successful element of support in physical education (Block et al., 2001, Klavina and Block, 2008). With correct training of the peer tutor students, it is evident that students with different types and severity of disabilities can be included in GPE (Block et al., 2001; Lieberman et al., 2000; Klavina, 2008). Other programmes available to help build awareness, understanding and cooperation between students are the Paralympic School Day, Awareness Days and Special Olympics Unified Games. Special needs assistants are increasingly being employed in schools in Ireland. With increased training in IPE, this support could be maximised in assisting the students and the teacher (Davis et al., 2007).

APE specialists are a fundamental support and resource for including students with disabilities in GPE (Lytle \& Hutchinson, 2004; Lytle \& Collier, 2002; Kudláček et al., 2008). Developing study programs at universities and teacher training institutions specialising in Adapted Physical Education/Activity would be greatly beneficial. Having study programs in APE would encourage more people to work in this area and raise the competence level of European professionals. Various studies revealed in the review that teachers found including all students in outdoor lessons more difficult due to issues of accessibility (Morley et al, 2005). The facilities and equipment need to be adapted to ensure participation of all students (Fejgin et al., 2005). Research that mirrors that of Davis et al. (2007) is needed in Europe, to establish the current status and training needs of SEN assistants. Peer tutoring studies could follow Klavina and Block (2008) and focusing on different peer tutoring interventions within the GPE environment. 
Research looking at the attitudes of GPE teachers, Primary teachers and students with and without disabilities is needed to identify the needs of European educators and students. Research investigating the adequacy of the Primary and Physical Education teachers' preparation and their willingness to develop an inclusive environment is critical if there is to be a positive future for inclusive physical education across the diverse and changing society that is contemporary Europe.

\section{Perspective Paragraph}

Inclusion in physical education can effectively work for the child with a disability (Goodwin \& Watkinson, 2000) and it can work without negatively affecting peers without disabilities (Faison-Hodge \& Porretta, 2004; Obrusníková et al., 2003). The success of inclusion is greatly increased when various factors such as support, personnel, training and positive attitudes exist. Studies showed successful and positive inclusive practice could be achieved in GPE even when sometimes all of the aforementioned factors were not readily available (Obrusníková et al., 2003). Europe is in the process of making a positive move towards greater inclusion of students with both mild to severe disabilities. Legislation is the vital tool to success, as it creates the blueprints for schools and communities to follow. If governments and professional organisations in Europe will support inclusive PE ultimately the experience of GPE of students with disabilities is likely to improve.

\section{REFERENCES}

Ajzen, I. (1991). The theory of planned behavior. Organizational Behavior and Human Decision Processes, 50, 179-211.

BAALPE. (1996). Physical Education for Pupils with Special Educational Needs in Mainstream Education. West Midlands: The British Association of Advisors and Lecturers in Physical Education.

Block, M. (1995). Development and validation of the children's attitudes toward integrated physical education-revised (CAIPE-R) inventory. Adapted Physical Activity Quarterly, 12, 60-77.
Block, M.E, (2007). A Teacher's Guide to Including Students with Disabilities in General Physical Education. (3rd ed). Baltimore: Paul H. Brookes Publishing Co.

Block, M.E., Conatser, P., Montgomery, R., Flynn, L., Munson, D., \& Dease, R. (2001). Effects of Middle School-Aged Partners on the Motor and Affective Behaviors of Students with Severe Disabilities. Palaestra, 17 (4), 34-39.

Block, M.E, \& Krebs, P. (1992). An Alternative to the Continuum of the Least Restrictive Adapted Physical Activity Quarterly, 9, 97-113.

Block, M.E, \& Obrusníková, I. (2007). Inclusion in Physical Education: A Review of the Literature From 1995-2005. Adapted Physical Activity Quarterly, 24, 103-124.

Block, M.E, \& Vogler, E.W. (1994). Inclusion in regular physical education: The research base. Journal of Physical Education, Recreation and Dance, 65(1), 40-44.

Davis, R.W., Kotecki, J.E., Harvey, M.W., \& Oliver, A. (2007). Responsibilities and Training Needs of Paraeducators in Physical Education. Adapted Physical Activity Quarterly, 24, 70-83.

Douthwaite, R. (1990). Meeting Special Needs in Mainstream Schools: A Case Study. British Journal of Physical Education, 21 (4), 393-396.

Dunkin, J. \& Biddle, B. (1974). The Study of Teaching. New York: Holt, Rinehart and Winston.

Faison-Hodge, J., \& Porretta, D.L. (2004). Physical Activity Levels of Students With Mental Retardation and Students Without Disabilities. Adapted Physical Activity Quarterly, 21, 139-152.

Fejgin, N., Talmor, R., \& Erlich, I. (2005). Inclusion and burnout in physical education. European Physical Education Review, Vol II (I), 29-50.

Fenrick, N.J., \& Peterson, T.K. (1984). Developing Positive Changes in Attitudes Towards Moderately/Severly Handicapped Students Through a Peer Tutoring Program. Education and Training of the Mentally Retarded, 19, 83-90. 
Goodwin, D.L., \& Watkinson, E.J. (2000). Inclusive Physical Education From the Perspective of Students With Physical Disabilities. Adapted Physical Activity Quarterly, 17, 144-160.

Grenier, M. (2006). A Social Constructionist Perspective of Teaching and Learning in Inclusive Physical Education. Adapted Physical Activity Quarterly, 23, 245-260.

Hardin \& Brent. (2005). Physical Education Teachers' Reflections on Preparation for Inclusion. Physical Educator, 62 (1).

Hodge, S.R., Ammah, J.O.A., Casebolt, K., Lamaster, K., \& O'Sullivan, M. (2004). High School General Physical Education Teachers' Behaviors and Beliefs Associated with Inclusion. Sport, Education and Society, 9(3), 395-419.

Hodge, S.R, Murata, N.M., \& Kozub, F.M. (2002). Physical Educators' Judgements About Inclusion: A New Instrument for Preservice Teachers. Adapted Physical Education Quarterly, 19, 435-452.

Hodge, S.R., Tannehill, D., \& Kluge, M.A. (2003). Exploring the Meaning of Practicum Experiences for PETE Students. Adapted Physical Activity Quarterly, 20, 381-399.

Hutzler, Y., Fliess, O., Chacham, A., \& Van den Auweele, Y. (2002). Perspectives of Children With Physical Disabilities on Inclusion and Empowerment: Supporting and Limiting Factors. Adapted Physical Activity Quarterly, 19, 300-317.

Kalyvas, V., \& Reid, G. (2003). Sport Adaptation, Participation, and Enjoyment of Students With and Without Physical Disabilities. Adapted Physical Activity Quarterly, 20, 182-199.

Klavina, A. (2008). Using peer-mediated instructions for students with severe and multiple disabilities in inclusive physical education: A multiple case study. European Journal of Adapted Physical Activity, 1(2), 7-19.

Klavina, A. \& Block, M.E. (2008). The Effect of Peer Tutoring on Interaction Behaviors in Inclusive Physical Education. Adapted Physical Activity Quarterly, 25, 132-158.
Kodish, S., Kulinna, P.H., Martin, J., Pangrazi, R. \& Darst, P. (2006). Determinants of Physical Activity in an Inclusive Setting. Adapted Physical Activity Quarterly, 23, 390-409.

Kozub, F. M., Sherblom, P. R., \& Perry, T. L. (1999). Inclusion Paradigms and Perspectives: A Stepping Stone to Accepting Learner Diversity In Physical Education. QUEST, 51, 346-354.

Kudláček, M. (2006a). Components of Attitudes Toward Inclusion of Students with Physical Disabilities in Physical Education in the Revised "ATIPDPE-R" Instrument/Scale for Prospective Czech Educators. Acta Universitatis Palackianae Olomucensis, 37(1), 13-18.

Kudláček, M. (2006b). State of knowledge about inclusion of children with disabilities into general physical education. Proceedings of European Congress of Adapted Physical Activities. (Available Online at www.eufapa.eu)

Kudláček, M., Ješina, O, Štěrbová, D. \& Sherrill, C. (2008). The nature of work and roles of public school adapted physical educators in the United States. European Journal of

Adapted Physical Activity, 1(2), 45-55.

Kudláček, M., Sherrill, C., \& Válková, H. (2002). Components/Indicators of Attitudes Toward Inclusion of Students with Physical Disabilities in PE in the ATIPDPE Instrument/Scale for Prospective Czech Physical Educators. Acta Universitatis Palackianae Olomucensis, 32 (2), 35-39.

Lieberman, L.J., Dunn, J.M., van der Mars, H., \& McCubbin, J. (2000). Peer Tutors' Effects on Activity Levels of Deaf Students in Inclusive Elementary Physical Education. Adapted Physical Activity Quarterly, 17, 2039.

Lieberman, L. J., \& Houston-Wilson, C. (2002). Strategies for Inclusion, A Handbook for Physcial Educators. U.S.A: Human Kinetics.

Lieberman, L.J., Houston-Wilson, C., \& Kozub, F.M. (2002). Perceived Barriers to Including Students With Visual Impairments in General Physical Education. Adapted Physical Activity Quarterly, 19, 364-377. 
Lienert, C., Sherrill, C., \& Myers, B. (2001). Physical Educator's Concerns About Integrating Children With Disabilities: A Cross-Cultural Comparison. Adapted Physical Activity Quarterly, 18, 1-17.

Lytle, R.K., Collier, D. (2002). The Consultation Process: Adapted Physical Education Specialists' Perceptions. Adapted Physical Activity Quarterly, 19, 261-279.

Lytle, R.K., \& Hutchinson, G.E. (2004). Adapted Physical Educators: The Multiple Roles of Consultants. Adapted Physical Activity Quarterly, 21, 34-49.

Meegan, S., \& MacPhail, A. (2006). Irish physical educators' attitude toward teaching students with special educational needs. European Physical Education Review , 12 (1), 75-97.

Miller, S. (1994). Inclusion of children with disabilities: can we meet the challenge? Physical Educator , 51 (1).

Moffett, A.C., Alexander, M.G.F., \& Dummer, G.M. (2006). Teaching Social Skills and Assertiveness to Students with Disabilities. Teaching Elementary Physical Education, 43-47.

Morley, D., Bailey, R., Tan, J., \& Cooke, B. (2005). Inclusive Physical Education: teacher's views of including pupils with Special Educational Needs and/or disabilities in Physical Education. European Education Review, Vol II(I), 84-107.

Murata, N.M., \& Jansma, P. (1997). Influence of support personnel on students with and without disabilties in general physical education. Clinical Kinesiology, 51 (2), 3746.

Obrusníková, I., Válková, H., \& Block, M.E. (2003). Impact of Inclusion in General Physical Education on Students Without Disabilities. Adapted Physical Activity Quarterly, 20, 230-245.

Place, K., \& Hodge, S.R. (2001). Social Inclusion of Students With Physical Disabilities in General Physical Education: A Behavioral Analysis. Adapted Physical Activity Quarterly, 18, 389-404.

Sherrill, C. (2004). Adapted physical activity, recreation and sport: Crossdisciplinary and lifespan (6th ed.). Boston, MA: McGraw-
Hill Higher Education.Smith, A. (2004). The inclusion of pupils with special educational needs in secondary school physical education. Physical Education and Sport Pedagogy, 9 (1), 37-53.

Stainback, W., \& Stainback, S. (1996). Inclusion: A Guide for Educators. Baltimore: Brookes Publishing Co.

Verderber, J.M.S., Rizzo, T.L., \& Sherrill, C. (2003). Assessing Students Intention to Participate in Inclusive Physical Education. Adapted Physical Activity Quarterly, 20, 2645.

Ward, P., \& Ayvazo, S. (2006). Classwide Peer Tutoring in Physical Education: Assessing Its Effects With Kindergartners With Autism. Adapted Physical Activity Quarterly, 23, 233-244.

Corresponding author's e-mail address: martin.kudlacek@upol.cz

The study has been supported by the research grant from Ministry of Education, Youth and Sports of the Czech Republic (No. MSMT 6198959221) "Physical Activity and Inactivity of the Inhabitants of the Czech Republic in the Context of Behavioral Changes" 


\section{EIN LITERATURÜBERBLICK ZUR INKLUSION VON SCHÜLERN MIT BEHINDERUNGEN IN DER SCHULISCHEN BEWEGUNGSERZIEHUNG AUS EUROPÄISCHER PERSPEKTIVE}

(Resümee)

Der Status der Inklusion von Schüler/innen mit Behinderung im allgemeinen Unterricht für Bewegung und Sport variiert stark über die einzelnen Europäischen Länder, und in vielen Ländern steckt die inklusive Bewegungserziehung noch in den Kinderschuhen. Die Absicht dieser Studie ist es, einen Überblick über die in Englisch publizierte Literatur, die auf die Inklusion von Schüler/innen mit und ohne Behinderung in der Bewegungserziehung fokussiert ist, zu geben - mit dem weiterführenden Anliegen, Empfehlungen zur Erleichterung der Inklusion in Europa zu entwickeln. Der Überblick reicht über einen Zeitraum von acht Jahren, beginnend mit 2000. Die Artikel hatten bestimmten Auswahlkriterien zu entsprechen. 27 Artikel entsprachen. Die vorgestellte Recherche basiert auf dem theoretischen Modell Study of Classroom Teaching (Dunkin \& Biddle, 1974), das empfiehlt, dass Untersuchungen über Lehren und Lernen vier Kategorien an Variablen einschließen sollen: Personale Vorbedingung (Lehrer), Kontext (Schüler), Prozess (Interaktion) und Produkt. Jede Grundkategorie von Variablen hat nachfolgende Untersektionen. Ein wichtiger Teil des Überblicks sind Empfehlungen und Anleitungen an Praktiker in Adapted Physical Education, Bewegungserzieher und Schulverwalter über öffentliche Grundsätze und erfolgreiche Praxis der inklusiven Bewegungserziehung in Europa.

SCHLÜSSELWÖRTER: Bewegungserziehung, Bewegung, Integration, Inklusion, Mainstream, Behinderung.

\section{REVUE DE LITTERATURE SUR L'INCLUSION DES ELEVES EN SITUATION DE HANDICAP EN EPS SELON UNE PERSPECTIVE EUROPÉENNE \\ (Résumé)}

L'état de l'intégration des élèves handicapés en Education Physique et Sportive ordinaire varie selon les pays européens et dans de nombreux pays, l'éducation physique inclusive est encore aux premières étapes. Le but de cette étude est de mener une revue de la littérature publiée en anglais portant sur l'intégration des élèves handicapés ou non, en éducation physique, avec l'intention d'élaborer des recommandations pour faciliter l'intégration en l'Europe. L'étude s'étend sur une période de huit ans commençant au début de l'année 2000. Les articles devaient répondre à des critères de sélection pour être inclus dans l'étude. Vingt-sept articles ont répondu aux critères. Notre revue de littérature s'est appuyée sur le modèle théorique sur l'étude de l'enseignement en classe (Dunkin et Biddle, 1974) qui suggère que l'étude de l'enseignement et de l'apprentissage concerne quatre catégories de variables: presage (enseignant), le contexte (les élèves), le processus (interaction) et le produit. Chaque domaine clé de variables comprend des sous-sections. Une partie importante de cette étude concerne des recommandations pour orienter les professionnels de l'éducation physique, les professeurs d'éducation physique et des administrateurs scolaires sur les politiques publiques, sur les bonnes pratiques liées à l'intégration en éducation physique en Europe.

MOTS CLEFS : Education physique, activité physique, intégration, inclusion, déficiences. 